\title{
EL RENACER DE ALEJANDRÍA EN EL SIGLO XIX A LA LUZ DE LOS OBSERVADORES HISPÁNICOS
}

\author{
Pablo Martín Asuero
}

Resumen: A lo largo del siglo XIX, Alejandría se convierte en un puerto importante en el Mediterráneo desde donde se enviaba a Europa el algodón, y en un centro estratégico para las comunicaciones con el Asia y el Pacífico a través del Canal de Suez, siendo especialmente importante para los espańoles por agilizar el trayecto a Filipinas. Los observadores españoles dan noticia de los cambios en una ciudad que mantiene restos de su pasado marcado por la presencia de Alejandro, Cleopatra, César, Marco Antonio u Octavio.

Palabras clave: España, Alejandría, Suez, algodón, viajeros, diplomáticos, arqueólogos, ruinas, obeliscos.

\section{THE REBIRTH OF ALEXANDRIA IN THE NINETEENTH CENTURY IN THE LIGHT OF HISPANIC OBSERVERS}

Abstract: All along the 19th century Alaxandria becomes an important port in the Mediterranean from where cotton was sent to Europe and in strategic center for the communications with Asia and Pacific through Suez, that was specially important for the Spaniards as made the passage to the Philippines faster. The Spanish observers will give notices of the changes in a city that kept rest of its past marked by the presence of Alexander, Cleopatra, Caesar, Marcus Antonius and Octavius.

Keywords: Spain, Alexandria, Suez, cotton, travelers, diplomats, archaeologist, ruins, obelisks.

Recibido: 22.03.13 - Aceptado: 29.04.13

Correspondencia: PABlo MARTín Asuero. direst@cervantes.es Phd Universidad del País Vasco. Director Instituto Cervantes en Estambul. Dirección postal Tarlavasi Bulvari, Zambak Sokak 25. CP 34435 Estambul. 
lo largo del siglo XIX Egipto se convierte, no sólo en un destino 1 turístico, sino también en un lugar de paso hacia el extremo Oriente, 1 primero por tierra a través del istmo de Suez, a partir de 1869, por el canal, un camino que acortaba el tiempo y el uso de los carburantes en los desplazamientos a China y Filipinas. En este contexto, y con las mejoras económicas de esta provincia otomana realizadas por Muhammad Ali y sus descendientes ${ }^{1}$, podemos encontrar toda una serie de textos en espańol realizados por diplomáticos, comerciantes, viajeros ${ }^{2}$, periodistas o peregrinos que, dentro del viaje a Tierra Santa, hacían un alto en Egipto. A partir de ese corpus textual y sin dejar de lado las referencias de manuales de historia o geografía, enciclopedias ${ }^{3}$ y atlas, podemos recuperar las imágenes sobre Alejandría recreadas por nuestros antepasados del mundo del espańol.

Uno de los primeros en llegar, en 1806, fue Domingo Badía, Al Bey, en un momento muy cercano a la retirada de las tropas de Bonaparte de Egipto y un año más tarde en que Muhammad Alí había sido reconocido por Estambul como gobernador de Egipto, iniciándose de esta manera una nueva fase en esta provincia otomana bajo el mando de este soberano y sus descendientes los jedives. Badía, como muchos otros, hace un breve resumen de esta ciudad, centrándose en su fase ptolemaica y romana, de la cual quedaba muy poco: [...] la columna de Pompeyo, los obeliscos de Cleopatra, las cisternas, catacumbas y algunas columnas enteras o hechas pedazos, esparcidas aquí y allá, son los restos de su antiguo esplendor" ${ }^{\prime 4}$. Este viajero muestra así su desencanto ante el hecho de

${ }^{1}$ F. Robert Hunter, Egypt under the Khedives, 1805-1879: from Housebold Governement to Modern Bureaucracy, Cairo 1999; Robert Mantran: Histoire de l'Empire Ottoman, Poitiers 1984; Strandford \& Ezel Shaw, History of the Ottoman Empire and Modern Turkey, vol. II: Reform, Revolution and Republic, the Rise of Modern Turkey 1808 1975, Cambridge 1977.

2 Carlos García-Romeral Pérez, Bio-Bibliografía de Viajeros Españoles (Siglo XIX), Madrid 1995; Lily Ltvak, El Ajedrez de Estrellas, crónica de los viajeros españoles en el siglo XIX por países exóticos (1800-1913), Barcelona 1886.

${ }^{3}$ Diccionario enciclopédico hispano-americano, Barcelona 1887-1898; ap. I, 1898 - 1899, ap. II, 1907-1910.

${ }^{4}$ Domingo Badía, Viajes por Marruecos, Trípoli, Grecia y Egipto, Palma de Mallorca 1994, p. 234. 
encontrar una población de cinco mil habitantes, de todos los colores, naciones y cultos, pero con un comercio moribundo y mal abastecida de agua.

A pesar de todo, Alejandría conservaba una presencia europea: "La calle de los Francos no desdiría de cualquier gran ciudad de Europa, y no es la única de esta clase que se halla en Alejandría"s. Posteriormente, sin embargo, afirma que las calles no estaban empedradas y que las casas no tenían ventanas, sino celosías. Según este observador, la población era local: "La masa principal de los habitantes de Alejandría se compone de árabes, es decir, de hombres generalmente ignorantes y groseros; pero lejos de ser indóciles y malos con los cristianos, les sirven aún y sufren sus caprichos e injusticias como si fueran esclavos"6. La explicación que da a esta extraña actitud reside en que, tras la ocupación napoleónica y el intento de invasión de los ingleses, se habían dado cuenta de la superioridad de los europeos en lo referente a las artes militares, la ciencia o el pensamiento político.

Esta situación cambia cuando, gracias a las buenas relaciones del Imperio Otomano con la Europa liberal, ésta considera el paso por el istmo de Suez como una forma de llegar al extremo Oriente. Uno de los primeros en dar testimonio es el comerciante Domingo Ortiz de Zárate en 1846, que afirma que por entonces había dos hoteles situados en la Plaza de los Cónsules, la cual era de aspecto europeo por el tamaño y estilo de los edificios: "pero en saliendo de la plaza no se ve más que una ciudad de moros, con calles estrechas y casas de mucha elevación, con ruines ventanas de empolvadas celosías, de un aspecto melancólico y triste [...]"7. La Plaza de los Cónsules se convertirá en el corazón de la ciudad, el lugar donde vivía y trabajaba la colonia europea, principalmente griegos e italianos y los diplomáticos, como el cónsul de España, Annibal Petrachi. Domingo Ortiz de Zárate nos describe a la familia de este italiano, aportándonos así un bello retrato de una sociedad levantina en una ciudad abierta al Mediterráneo:

"El cónsul español nos ofreció su casa cuando le fuimos a presentar los pasaportes y al día siguiente tuvimos el gusto de ir a visitarlo tres españoles y la señorita doña Rosa Mier. Nos recibió en un magnífico salón con sofás de muelles forrados de cerda de una vara de ancho prolongados por todo el recinto. Una alfombra de Persia cubría el suelo, y grandes espejos, bruñidas mesas y un soberbio piano contemplaban el adorno de tan bella estancia. El

\footnotetext{
${ }^{5}$ BADÍA, o. c., p. 234.

${ }^{6}$ BAdía, o. c., p. 235.

${ }^{7}$ Domingo Ortiz de Zárate, Viaje por el Istmo de Suez desde China a Europa, Manila 1848, p. 53.
} 
Pablo Martín Asuero: El renacer de Alejandría en el siglo XIX a la luz de los observadores...

cónsul, su señora y familia nos salieron a recibir a la puerta de la sala y apenas nos sentamos, se prepararon dos esclavas que nos sirvieron café y la pipa turca: las tazas de café eran de porcelana de China muy pequeñas, sin platillo, metidas en su filigrana de plata. La mujer del cónsul es turca y estaba sentada en el sofá a su usanza con las piernas cruzadas, el atavío y la magnificencia turca, que daba a su hermosura oriental un singular realce. Se hallaba vestida con un gracioso turbante, un collar de perlas en su blanco cuello, chaqueta o corpiño ajustado de terciopelo azul turquí bordado de oro y puñal con el puño de diamantes en la cintura. La bella turca hablaba el italiano y en ese idioma suplicó a la niña Rosa Mier que cantase alguna cosa, y deseosa de complacerla, se sentó al piano, tocó un rato y cantó en seguida algunas canciones españolas"8.

Diez años más tarde, los comentarios de un abogado leridano, Diego Joaquín Ballester, dan testimonio de que Alejandría ha adquirido un cierto grado de bienestar, con cafés, hoteles, peluquerías, ruinas de interés turístico y un ferrocarril con el cual se podía desplazar a El Cairo por el módico precio de 150 reales en segunda clase. El tren salía a las nueve de la mañana y tras una parada de media hora para almorzar a orillas del Nilo, llegaba a su destino a las tres y media de la tarde. Ese mismo viajero señala que, como en muchas otras ciudades de Oriente, había servicios postales franceses, ingleses, austriacos y turcos?

Hay que tener en cuenta que en Alejandría estaba la bolsa del algodón que se cultivaba en el delta del Nilo y el puerto desde donde se expendía esta materia textil, especialmente a partir de la Guerra Civil de Norteamérica (1861-1867) en que los mercados europeos se aprovisionaban del algodón egipcio cuando dejaron de llegar las remesas norteamericanas. El diplomático español Antonio Bernal de O’Reilly llegó en 1864, dejando constancia de lo que era una ciudad en plena expansión económica. En ese momento Alejandría era una encrucijada entre Europa y el lejano Oriente orientada hacia el norte del Mediterráneo. Así, Antonio Bernal dice que los hoteles no eran gran cosa y eran caros, y cita los nombre de ocho: Abat, de Europa, Peninsular, Oriental, Victoria, Nord y de Inglaterra ${ }^{10}$.

Según este diplomático, los turistas, colonia extranjera y comerciantes podían divertirse en toda una serie de cafés cantantes, restaurantes y en dos teatros, el

${ }^{8}$ Ortiz de Zárate, o. c. p. 55.

${ }^{9}$ Diego Ballester, Viatge a Terra Santa, Egipte i Turquia (1857), Lérida 1999. p. 120.

${ }^{10}$ Antonio Bernal de O'Reilly, Viaje a Oriente, en Egipto, Madrid 1876, p. 85Viaje a Oriente, en Egipto, Madrid 1876, p. 85. 
Rossini y el Zizinia, que costaba 16 duros el palco o 10 reales la entrada: “[...] lo que no impide que esté siempre concurrido y lleno de mujeres hermosas, luciendo ricos brillantes con profusión, sobre todo las griegas, que deslumbran al mirarlas; desplegando a cual más un lujo de trajes que nos transporta insensiblemente a las solemnidades mayores de París, de Madrid, de Londres o de Viena ${ }^{11}$.

La principal diversión de Alejandría eran los paseos, especialmente los jardines de Rosetta, el canal de Mahmudieh que a lo largo de 78 kilómetros unía el Nilo con Alejandría y la Plaza de los cónsules, con dos hileras de árboles formando dos paseos laterales y un salón central dotado de dos fuentes de ancha taza a cada extremo. Para facilitar el tránsito había dos calles espaciosas para los coches de caballos y dos plazas para estacionar los carruajes. En esta plaza se encontraban la mayoría de los hoteles, consulados, iglesias y la banca ${ }^{12}$, permitiendo al observador entrar en contacto con una sociedad alejandrina cada vez más cosmopolita:

"Allí se mezcla el dominó negro, que representa el habbarrach o manto con que se cubren las coquetas levantinas; el de color de rosa, el encarnado, el azul y el violeta de las hijas de Egipto y Stambul; el blanco, como vestales, de las de Siria, con las tocas de las beatas y hermanas de la Caridad. Todos los ropajes y trajes más vistosos del Oriente aparecen entre el austero capuchino; el padre franciscano de Tierra-Santa; el negro balandrán del misionero; el carmelita y el dominico, procedentes de Manila, que conservan sus hábitos, permitidos entre los moros pero no entre nosotros cristianos [...] el modesto y escuálido frac negro; la rabicorta chaqueta a la tudesca o italiana; el plaid escocés y el makfarlain británico que pulula en todas partes"13.

La inauguración del canal de Suez en 1869 atrajo el interés de los invitados al evento, como el español José de Castro, que afirma que la población de Alejandría era de 200.000 habitantes ${ }^{14}$. Juan de Dios de la Rada, dos ańos más tarde, aporta la misma cifra señalando que había pasado de 6.000 a principios del siglo XIX a los 200.000, de los cuales 5.000 eran extranjeros ${ }^{15}$.

\footnotetext{
${ }^{11}$ Bernal de O'Reilly, o.c., p. 91.

${ }^{12}$ Bernal de O'Reilly, o.c., p. 86.

${ }^{13}$ Bernal de O'Reilly, o.c., p.87.

${ }^{14}$ José Castro Serrano, Novela del Egipto, Madrid 1870, p. 87.

${ }^{15}$ Juan de Dios de la Rada Delgado, Viaje a Oriente de la fragata de guerra Arapiles, Barcelona 1876-1783, vol. 3, p. 187.
} 
Pablo Martín Asuero: El renacer de Alejandría en el siglo XIX a la luz de los observadores...

Dos profesores de la Universidad de Santiago que estuvieron en Alejandría en 1875 aportan también toda una serie de datos sobre la importancia de esta ciudad como puerto comercial, en el que en 1872 recalaron 2.953 barcos, de ellos, 526 vapores correos, principalmente ingleses, franceses y austriacos, y 2.400 buques mercantes. El valor de las importaciones se estimaba en casi seiscientos millones de piastras, y el de las exportaciones, en 1.330.483.809 piastras, explicando que la piastra equivalía a 67 céntimos de real ${ }^{16}$. Se exportaron principalmente algodón, azúcar, trigo, dátiles, café, linaza, gomas, marfil, madreperla y lana, y se importaron productos manufacturados, maderas y alimentos. Según los datos que les proporcionaban, los banqueros de Alejandría disponían de un capital de 1.500.000.000 reales en las diferentes plazas europeas y entre $1865 \mathrm{y}$ 1875 se había exportado por valor de 5.200.000.000. En aquel momento había en Alejandría 37 fábricas de tejidos de algodón, y otras de seda, de tapices y perfumerías, al margen de los mercados tradicionales ${ }^{17}$.

Estos mismos observadores se sorprenden por la cantidad de instituciones de educación, muchas de ellas de origen europeo. Aparte de las públicas, existían las privadas y las Escuelas de los Hermanos de la Doctrina Cristiana, las de las Hermanas de la Misericordia, el pensionado de los Padres de San Vicente de Paúl y las confesionales para los coptos, los griegos, los protestantes y, la más curiosa de todas, "¡hasta una de los francmasones!” ${ }^{18}$. Muchas de las instituciones tenían también hospitales, como las Hijas de San Vicente de Paúl o las Diaconisas de Kaiserwerth, las cuales aceptaban a todo tipo de paciente, independientemente de su credo, como el hospital civil o el militar. Por último, estos observadores señalan que Alejandría estaba comunicada con todo el mundo a través del The English Telegraph Company; de una compañía nacional de telégrafos y de barcos, no sólo con el Mediterráneo, sino con el Adriático, el Negro, el Rojo, el Golfo Pérsico, el océano Índico o Japón.

A pesar de las descripciones de los observadores españoles en las que Alejandría aparece como una extensión de Europa, la realidad era más compleja de la que exponen sus testimonios, existiendo profundas diferencias entre los europeos, sus protegidos y la población local. Dichas diferencias no eran sólo económicas, sino también legales, existiendo todo un complicado entramado de administración de

\footnotetext{
${ }^{16}$ José Ma. Fernández Sánchez-Francisco Freire Barreiro, Santiago, Jerusalén, Roma. Diario de una peregrinación a estos y otros santos lugares, Santiago 1880, p. 470.

${ }^{17}$ Fernández Sánchez-Freire Barreiro, o. c., pp. 523-524.

${ }^{18}$ Fernández Sánchez-Freire Barreiro, o. c., p. 524-525.
} 
justicia con tribunales mixtos, egipcios y el papel de los cónsules. La situación no tardó en explotar con la revuelta de Urabi en 1882, un oficial del ejército egipcio formado en la Universidad de Al Azhar en El Cairo, harto de las arbitrariedades de las potencias y de la ineficacia del jedive. De esta manera, y en el marco de un Imperio Otomano que había visto cómo se independizaba la mayoría de los Balcanes tras la guerra ruso-turca de $1877-1878$, se rebeló contra el monarca proponiendo una vuelta a los valores tradicionales islámicos y una distancia con Europa. Ante esta reacción nacionalista, en la cual se ponía en cuestión el papel del soberano y sus reformas modernizadoras, Francia e Inglaterra no tardaron en unir sus fuerzas, enviando su flota a Alejandría en mayo de 1882. Allí exigieron la dimisión de Urabi y su posterior exilio. La situación, lejos de calmarse, derivó en violentos ataques a intereses europeos en la ciudad y el posterior bombardeo de la misma por parte de la flota británica el 17 de julio, quedando la hermosa Plaza de los cónsules reducida a escombros ${ }^{19}$. Los lectores espańoles pudieron estar al tanto de estos acontecimientos a través de los periódicos como La Época de Madrid, que se hizo eco de lo que se denominaba "la cuestión de Egipto", como una parte de la "cuestión de Oriente”. Lógicamente, este diario liberal toma un partido contrario a los valores imperialistas: "El Egipto para los egipcios, con salvaguardia para los intereses europeos" ${ }^{20}$. Poco después, los lectores de La Época se encontraron en la portada la crónica "Los sucesos de Alejandría” con noticias de la revuelta ${ }^{21}$. Estas noticias interesaban bastante en España, no tanto por la suerte de los alejandrinos, sino por la situación del canal de Suez, vía utilizada para ir a Filipinas. Por eso, el hecho de que el día 16 la situación estuviera controlada fue considerada una buena noticia para los intereses nacionales ${ }^{22}$. Sin embargo, la presencia británica estaba vista con suspicacia, especialmente por Alemania e Italia, al no quedar claro hasta cuándo tenían pensado permanecer en Egipto y si habían actuado al margen del derecho internacional.

Lo cierto es que, poco después, hicieron su aparición tropas alemanas con el objeto de proteger su hospital, y norteamericanas, interesadas en crear un consulado en Alejandría ${ }^{23}$. Días más tarde Francia envió 15.000 hombres procedentes de Túnez, Argelia y Toulon al mando del general Thomassin, Italia,

${ }^{19}$ M. E. YAPP, The Making of the Modern Near East 1792-1923, London: Logman 1987, pp. 223-225.

${ }^{20}$ La Época, 11 de julio de 1882.

${ }^{21}$ La Epoca, 14 de julio de 1882.

${ }^{22}$ La Epoca, 16 de julio de 1882.

${ }^{23}$ La Epoca, 17 de julio de 1882. 
Pablo Martín Asuero: El renacer de Alejandría en el siglo XIX a la luz de los observadores...

cinco acorazados, y "España, a pesar del lamentable estado de nuestra marina, ha enviado algunos buques, y se hacen preparativos para poner en movimiento el mayor número posible de barcos de guerra" ${ }^{24}$. Con la derrota de las tropas de Urabi en septiembre, el sultán de Estambul terminó por aceptar una ocupación militar británica que, paradójicamente, reconocía la soberanía otomana de Egipto.

Euardo Toda Güell llegó a Alejandría poco después, en 1884. Por lo que cuenta este diplomático, la ciudad se iba recuperando, existiendo una colonia de 50.000 cristianos, los cuales vestían a la europea, y un puerto visitado anualmente por dos mil barcos cuyas operaciones de importación y exportación ascendían a quinientos millones de pesetas ${ }^{25}$. Este mismo autor cuenta la sublevación de Urabi, el desembarco inglés y los cien millones de pesetas de indemnización que se fijaron ${ }^{26}$.

Una versión similar de los hechos se puede encontrar en el tomo primero del Diccionario Enciclopédico Hispano-Americano, fechado en 1887, el cual dedica tres páginas y un plano a Alejandría. Efectivamente, Alejandría resurgió de sus cenizas en poco tiempo. Así, según la versión francesa de la guía Baedeker de 1914, se podía llegar allí en barco desde los principales puertos mediterráneos, como Marsella, Nápoles, el puerto del Imperio Austro-Húngaro de Trieste o Estambul, que enlazaba Alejandría con el Mar Negro, Rusia y Rumania. Esta misma guía aporta las direcciones de diez hoteles, cafés, restaurantes, cervecerías, bares, librerías, hospitales, tiendas de material fotográfico, teatros, iglesias, y las de los consulados de Francia, Inglaterra, Alemania, Austria-Hungría, Dinamarca, Bélgica, Grecia, Italia, Países Bajos, Suecia, Rusia y Estados Unidos.

Todo desplazamiento se realiza condicionado por los conocimientos previos que tenemos del espacio que vamos a conocer, Por eso, a menudo, cuando llegamos al punto de destino se produce un desencanto, ya que suele ocurrir que lo que encontramos no tiene nada que ver con lo que esperábamos. En el caso de Alejandría dicho conocimiento es, básicamente, histórico, al estar ligado a tres personas cuyo recuerdo perdura en nuestras mentes: Alejandro, Marco Antonio y Cleopatra. En estas circunstancias, se comprende que la mayoría de los viajeros hagan un resumen histórico de la ciudad. Uno de los más completos es el de Juan de Dios de la Rada, un importante intelectual de la segunda mitad del siglo XIX que fue el encargado de la memoria de la expedición de la fragata Arapiles

\footnotetext{
${ }^{24}$ La Época, 24 de julio de 1882.

${ }^{25}$ Eduardo Toda Güell, $A$ través del Egipto, Madrid 1889, pp. 13-14.

${ }^{26}$ TODA GÜELL, o.c., pp. 21-22.
} 
en 1781. De la Rada empieza por el principio (332 a. C.), cuando Alejandro, tras conquistar Memfis, encontró este puerto frecuentado por marinos griegos y fenicios. Este enclave era una especie de bastión que impedía el acceso a Egipto a los extranjeros. Alejandro se dio cuenta de su estratégica situación y mandó a Dinócrates la construcción de la ciudad y un puerto nuevo que, junto con el viejo, el lago Mareotis y la isla de Faros configuraban la costa alejandrina. Más tarde los Ptolomeos continuaron las obras, dotándola del famoso Faro, una de las siete maravillas del mundo. De la Rada se basa en la obra de Estrabón para la descripción de la ciudad en el año 24 a. C.: una calle de 35 metros de ancho atravesaba la ciudad de E. a O., lugar del emplazamiento de palacios, templos y otras magníficas construcciones, siendo cruzada por otra similar que iba del lago de Mareotis al puerto. Alejandría no era sólo una ciudad comercial, sino un centro cultural con numerosos templos, la celebérrima Biblioteca y el no menos importante Museo, la primera academia del mundo que sentó las bases de la Escuela de Alejandría, donde se daban cita filósofos, retóricos y gramáticos. Hay que tener en cuenta de que pocas ciudades pueden enorgullecerse de haber dado su nombre a un tipo de verso, en este caso, el alejandrino.

Siguiendo con la memoria científica de este observador español, en el año 204 a. C. Polomeo Epifanes buscó el apoyo del Senado romano contra las ambiciones de los reyes de Siria y Macedonia. Esta alianza permitió a César desembarcar en el año 47 a. C. con una tropa de 4.000 hombres con el pretexto de favorecer a Cleopatra en su lucha contra su hermano Ptolomeo XIV, y la consiguiente pérdida de la Biblioteca pasto de las llamas. Sin embargo, Cleopatra supo afianzarse en el trono, reconstruyó la Biblioteca y logró que le fueran transferidos los fondos de la de Pérgamo, 200.000 volúmenes que se colocaron en el Serapeum. De esta manera acababa con su rival y se convertía en la capital de la memoria.

Alejandría se convirtió en el segunda ciudad del Imperio Romano, con una población de 300.000 habitantes, de los cuales muchos eran judíos. Es más, logró mantener su esplendor hasta el siglo VII en que las tropas del califa Omar encontraron "[...] 4.000 palacios, otros tantos bańos públicos, 400 circos o plazas para regocijos populares y 12.000 jardines" ${ }^{27}$. A partir de ese momento la ciudad entra en una fase de decadencia: por una parte, se interrumpen las relaciones comerciales con los árabes, por otra, se abre una nueva ruta hacia las Indias doblando el cabo de Buena Esperanza.

\footnotetext{
${ }^{27}$ Toda GÜell, o. c., p. 185.
} 
Para Juan de Dios Rada en el siglo XIX y todavía para muchos de nosotros Alejandría no sería lo que esa si no hubiera sido el espacio donde tuvo lugar la historia de amor entre César, Cleopatra y Marco Antonio. De hecho está tan presente en las mentes de los observadores, que raro es el texto que no lo es dedica, al menos, varios párrafos. El diplomático y arqueólogo Eduardo Toda y Güell lo hace con buena parte del capítulo IV de su $A$ través del Egipto (1889). La historia comienza en el 52 a. C., año en que muere Ptolomeo Filopátor, dejando el cetro a su hijo Dionisio, Como éste era menor de edad, su hija Cleopatra fue nombrada regente, y la ciudad de Roma, ejecutora testamentaria de su última voluntad. Según nos cuenta nuestro diplomático, se trataba de una mujer de armas tomar:

"Educada en la desgracia, pero imbuida desde niña en las ideas de predominio, de tener a sus pies el mando, de ser Reina en los palacios y Diosa en los templos, para realizar estas locas aspiraciones no se detuvo ante la falta, ni ante el escándalo, ni ante el mismo crimen. A la muerte de su padre, le faltó tiempo para intrigar contra su hermano que debía ocupar el trono, y aun osó alzarse en armas, pero vencida en el primer encuentro escapó a Siria en busca de un auxilio, que el cónsul romano JULIO CÉSAR le vendió a cambio de sus caricias" 28 .

César, en una evidente prueba del amor que le profesaba, logró acabar con su molesto hermano y además eliminó a otro que, en un momento dado, podría haber reclamado sus derechos sucesorios, para así sentarla sobre lo que Eduardo Toda llama "el carcomido trono de los faraones. Por si fuera poco, tuvieron un hijo, al cual le dieron el nombre de Cesarión: Y no satisfecha aún la ambición de CLEOPATRA, cuando supo que su amante gobernaba el mundo, fue presurosa a Roma para compartir con él sus glorias, pensando dar a su hijo la herencia del futuro imperio, y recibir ellos los honores supremos de la divinidad" 29 . Sin embargo, César esta vez fue capaz de resistirse sus encantos y la devolvió a Egipto, jurando ella vengarse por la afrenta cometida. Poco después, tras la confusión reinante con el asesinato de Julio César y la posterior guerra civil, Egipto quedó en sus manos. Cuando el triunviro la llamó al orden para que diera explicaciones de su rebeldía, ésta salió triunfante: "El general ilustre en cien batallas, indómito caudillo de las legiones romanas, que en aquella epopeya era

${ }^{28}$ TODA GÜELl, o. c., p. 61.

${ }^{29}$ Toda GÜELl, o- c., 61. 
ya un héroe digno de ocupar después la pluma de PLUTARCO, no pudo luchar contra la Reina egipcia, arrodillada a sus plantas, llenos los ojos de lágrimas, muda pero elocuente en su silencio, no implorando perdón, sólo atenta a infiltrar en el héroe el rayo ardiente de su amor y la lascivia que despedían sus pupilas, cada vez que levantaba los rosados párpados"30.

Marco Antonio la siguió a Alejandría, en donde se abandonaron a las pasiones en un palacio decorado con obeliscos y esfinges traídos de Heliópolis y Karnac y pasaron el invierno del año 441. Más tarde, aprovechando los éxitos militares de Marco Antonio, levantó el santuario de Ermouthis para rendir culto a su imagen simbolizada por una diosa del panteón osiriano. Octavio Augusto, viendo las maquinaciones de la amante de Marco Antonio, declaró la guerra a Egipto y les derrotó en Actio. Tras la derrota, como es sabido, cuando Cleopatra se enteró de la noticia de que Octavio entraba triunfante en Alejandría, se suicidó con un áspid ${ }^{31}$.

Cleopatra para nuestros viajeros del XIX es básicamente eso, una hermosa mujer con un ansia de poder desmedida y una soberbia tal, que le induce a convertirse en diosa, retar a Roma, seducir a César y a Antonio y acabar poniendo fin a su vida. Eduardo Toda lo deja muy claro al final del capítulo: “¡Cómo fascina lo pasado! De tanta ostentación y fastuoso poder, nada queda. Ni siquiera cuidó OCTAVIO de enterrar el cuerpo de CLEOPATRA"32.

Alejandría conservaba muy poco de su pasado en el siglo XIX: la necrópolis, muy bien descrita por Juan de Dios de la Rada, las catacumbas, al columna de Pompeyo y las agujas de Cleopatra. Estos dos últimos monumentos se convirtieron en una atracción turística, estando presentes en la mayoría de los textos. Un buen ejemplo de ello son José María Fernández Sánchez y Francisco Freire Barreiro, dos profesores de la Universidad de Santiago que peregrinaron a Tierra Santa en 1875 pasando también por Alejandría, que nos han dejado una buena descripción de los dos monumentos acompañada de sendos grabados. Así, dicen que la columna es un monolito de granito rojo de 22 metros de alto, 9 de circunferencia y 3 de diámetro, a la que se añadía un capitel corintio de 5 metros y 30 de superficie. Estos autores aportan la inscripción en griego, con una nota a pie de página con la traducción: "Pompeyo, gobernador de Egipto, erigió este monumento al santísimo autócrata, al protector de Alejandría, Diocleciano el invencible" 33 . Posteriormente aclaran que el Pompeyo en cuestión no era el

\footnotetext{
${ }^{30}$ TOdA GÜELL, o. c., p. 64.

${ }^{31}$ Toda GüEll, o. c., p. 69.

${ }^{32}$ Toda GÜEll, o. c., p. 69.

${ }^{33}$ Fernández Sánchez-Freire Barreiro, o. c., p. 486.
} 
Pablo Martín Asuero: El renacer de Alejandría en el siglo XIX a la luz de los observadores...

rival de César, sino un gobernador en tiempos de Diocleciano (284-305), el cual había ido a Egipto a perseguir a los cristianos. A dicha columna se encaramaron los sabios de Bonaparte y, según nuestros profesores, un grupo de catorce turistas ingleses habían tenido la humorada de acceder por medio de cuerdas y poleas.

Por lo que respecta a las agujas de Cleopatra, las definen como dos obeliscos de granito rojo de Siena: uno, de 21 metros, se mantenía erguido, mientras que el otro, caído en tierra tras el terremoto de 1303, era de 19 metros, con un diámetro en su base de poco más de 2 metros. Ambos procedían de Heliópolis, donde los había erigido Tutmosis III (1508-1493 a. C.) y de donde fueron llevados a Alejandría el 13 a. C., es decir bastante después de la muerte de Cleopatra, para colocarlos en le Caesareum. Los catedráticos fueron de los últimos en verlos en Alejandría, ya que Ismail bajá los regaló, uno a Nueva York, el otro a Londres (este último lo pudieron ver en una segunda ocasión en la parada que hizo en el puerto de Ferrol el barco que lo transportaba ${ }^{34}$. Muhammad Alí había ofrecido una de las agujas a Francia y otra a Gran Bretańa. Sin embargo, Francia prefirió quedarse con un obelisco de Luqsor, que desde 1836 adorna la plaza de la Concordia de París. Fue precisamente el efecto causado por este monumento en París el que hizo que los ingleses pidieran un obelisco en 1876. Un año más tarde el monumento, en un barco que no podía llamarse de otra forma que Cleopatra, dejaba el puerto de Alejandría remolcado por el Olga rumbo a Londres. Tras dos escalas en Argel y en Gibraltar, cuando ya estaban en aguas del golfo de Vizcaya, una tempestad hizo que se rompieran las amarras del Cleopatra, que quedó solo y a la deriva. Cuando ya se le daba por perdido con su preciada carga, los ingleses se enteraron por la prensa que había aparecido en Ferrol el 16 de octubre. Finalmente, remolcado por dos barcos de vapor pudo llegar a Londres, en donde el obelisco fue erigido en el Támesis, entre los puentes de Waterloo y Carring Cross ${ }^{35}$.

El viaje del otro obelisco fue menos accidentado, pero su salida provocó el rechazo de los alejandrinos y de los arqueólogos, que veían cómo la ciudad quedaba desprovista de los restos de su pasado. El jedive Ismail se lo había prometido a los Estados Unidos durante los fastos de la inauguración del canal de Suez en 1869. Diez años más tarde decidieron llevárselo y el 20 de julio de 1880 era erigido en el Parque Central de Nueva York. El 9 de octubre tuvo lugar una ceremonia masónica seguida por unos nueve mil miembros de las

${ }^{34}$ Fernández Sánchez-Freire Barreiro, o. c., pp. 498-500.

${ }^{35}$ Robert Solé, Le grand voyage de l'obelisque, París 2004, pp. 213-217. 
logias neoyorquinas, antes de la inauguración oficial, el 22 de enero siguiente, de lo que fue llamado "el monumento más antiguo del Nuevo Mundo". Pero la historia no termina aquí: como en Washington no había ningún monumento conmemorativo de Georges Washington, las logias masónicas se mostraron muy interesadas en erigir un obelisco al que fuera el primer presidente de los Estados Unidos en lo que se denominaría "el monumento masónico más grande del mundo", y así decidieron instalar en 1885, frente a la Casa Blanca, un obelisco de 169 metros de alto, una estructura de cemento recubierta de mármol blanco, equipada interiormente con una escalera y un ascensor a vapor.

\section{Referencias bibliográficas}

Badía, D. (1994) Viajes por Marruecos, Trípoli, Grecia y Egipto. Palma de Mallorca: Edit.Olañeta.

Ballester, D. (1999) Viatge a Terra Santa, Egipte i Turquia (1857), Lérida: Ed. Pagés.

Bernal de O’Reilly, A. (1876) Viaje a Oriente, en Egipto. Madrid: Librería de Victoriano Suárez.

Fernández Sánchez, J. M. y Freire Barreiro, F. (1880) Santiago, Jerusalén Roma. Diario de una peregrinación a estos y otros santos lugares. Santiago: Boletín Eclesiástico.

Castro Serrano, J. (1886) Novela del Egipto. Madrid: F. Fortanet Edit. GARCÍA-ROMERAL PÉREZ, C. (1886) Bio-Bibliografía de Viajeros Españoles (Siglo XIX). Madrid: Ollero \& Ramos Edit.

Hunter, F. R. (1999) Egypt under the Khedives, 1805-1879: from Housebold Governement to Modern Bureaucracy. Cairo: The American University in Cairo.

Litvak, L. (1886) El Ajedrez de Estrellas, crónica de los viajeros españoles en el siglo XIX por paises exóticos (1800-1913). Barcelona: Ed. Laila.

Mantran, R. (1984) Histoire de l'Empire Ottoman. Poitiers: Ediciones Fayard.

Ortiz de ZÁrate, D. (1848) Viaje por el Istmo de Suez desde China a Europa. Manila: Colegio de Santo Tomás.

Rada Delgado, J. de la (1876-1883) Viaje a Oriente de la fragata de guerra Arapiles.Barcelona: Emilio Robert y Cía. Edit., vol. 3. 
SHaw S. \& E. (1977) History of the Ottoman Empire and Modern Turkey, Vol. II: Reform, Revolution and Republic, the Rise of Modern Turkey 1808-1975. Cambridge: Cambridge University Press.

Toda GüEll, E. (1889) A través del Egipto. Madrid: Ed. El Progreso.

Varios Autores (1907-1910) Diccionario enciclopédico hispano-americano. Barcelona: Montaner y Simón Edit.

Yapp, M. E. (1987). The Making of the Modern Near East 1792-1923, London: Logman. 